\title{
Crescimento e produção da mamoneira cultivada sob diferentes níveis de salinidade da água de irrigação e doses de nitrogênio
}

\section{Growth and production of castor bean under different levels of irrigation water salinity and nitrogen doses}

\author{
Reginaldo Gomes Nobre ${ }^{1 *}$; Geovani Soares de Lima²; Hans Raj Gheyi³; \\ Lauriane Almeida dos Anjos Soares²; Saulo Soares da Silva \\ Alexsandro Oliveira da Silva ${ }^{4}$; Givanildo da Silva Lourenço ${ }^{4}$
}

\section{Resumo}

A mamoneira (Ricinus communis L.) é uma planta pertencente à família Euphorbiaceae que se destaca pela rusticidade e boa adaptação a condições adversas de clima e solo, apresentando rápido crescimento, elevada produção e considerável teor de óleo em suas sementes. Neste contexto, conduziuse esta pesquisa objetivando avaliar a influência da irrigação com água de diferentes concentrações salinas e doses de nitrogênio sobre o crescimento e a produção de mamoneira cv. BRS Energia. O experimento foi conduzido em lisímetros sob condições de campo, no Centro de Ciências e Tecnologia Agroalimentar da Universidade Federal de Campina Grande. Adotou-se o delineamento em blocos inteiramente casualizados em esquema fatorial 5 x 5, com três repetições. Os tratamentos consistiram da combinação de cinco níveis de condutividade elétrica da água de irrigação $(0,4 ; 1,4 ; 2,4 ; 3,4$ e 4,4 dS $\mathrm{m}^{-1}$ ) e cinco doses de nitrogênio $(50 ; 75 ; 100 ; 125$ e $150 \%$ da dose recomendada). O número de folhas, o diâmetro caulinar, a altura de planta, a fitomassa seca do caule e de folhas, e o número de frutos no racemo primário da mamoneira cv. BRS Energia foram afetados linear e negativamente pela salinidade da água a partir de $0,4 \mathrm{dS} \mathrm{m}^{-1}$; a fitomassa seca de folhas e a produção do racemo primário são as variáveis mais sensíveis ao estresse salino; doses crescentes de adubação nitrogenada promoveram, na colheita, aumento na fitomassa seca de caule e de folhas e no número de frutos no racemo primário; a aplicação de doses crescentes de nitrogênio reduziu o efeito da salinidade sobre o diâmetro de caule da mamoneira cv. BRS Energia.

Palavras-chave: Ricinus communis L., condutividade elétrica, nutrição mineral, salinidade

\begin{abstract}
The castor bean (Ricinus communis L.) is a plant belonging to the family Euphorbiaceae, and stands for the rusticity and adaptation to adverse conditions of climate and soil, for the fast growth, high production and considerable oil content in its seeds. In this context, this study we conducted to evaluate the effect of different levels of irrigation water of salinity and nitrogen on the growth and yield of castor bean cv. BRS Energia. The experiment was conducted in lysimeters under field conditions, at the Centro
\end{abstract}

1 Prof. da Unidade Acadêmica de Ciências Agrárias, Universidade Federal de Campina Grande, UFCG, Pombal, PB. E-mail: rgomesnobre@pq.cnpq.br

2 Discente(s) de Pós-graduação em Engenharia Agrícola, CTRN, UFCG, Campina Grande, PB. E-mail: geovanisoareslima@ gmail.com; laurispo@hotmail.com

3 Prof. Visitante Nacional Sênior, Universidade Federal do Recôncavo da Bahia, UFRB, Cruz das Almas, BA. E-mail: hans@ pq.cnpq.br

4 Discentes de Graduação em Agronomia, CCTA, UFCG, Pombal, PB. E-mail: saulo20-@hotmail.com; alexsandro.vip@hotmail. com; givanildo83@r7.com

* Autor para correspondência 
de Ciências e Tecnologia Agroalimentar, of Universidade Federal de Campina Grande. A complete randomized block design in a $5 \times 5$ factorial design with three replications. Treatments included a combination of five levels of electrical conductivity of irrigation water $(0.4,1.4,2.4,3.4$ and $4.4 \mathrm{dS}$ $\left.\mathrm{m}^{-1}\right)$ and five doses of nitrogen $(50,75 ; 100,125$ and $150 \%$ of the recommended dose). The number of leaves, stem diameter, plant height, dry mass of stems and leaves, and fruit number in primary raceme of castor bean cv. BRS Energia were linearly and negatively affected by irrigation water salinity from $0.4 \mathrm{dS} \mathrm{m}^{-1}$, the dry mass of leaves and production of primary cluster are variables more sensitive to salt stress, increasing doses of nitrogen fertilization promoted at harvest, increase in dry weight of stem and leaves and number of fruit in primary cluster; applying increasing doses of nitrogen reduced the effect of salinity on stem diameter of castor bean cv. BRS Energia.

Key words: Ricinus communis L., electrical conductivity, mineral nutrition, salinity

\section{Introdução}

Cerca de $40 \%$ de toda a energia consumida no mundo provém do petróleo, do carvão e do gás natural, no entanto, essas fontes são limitadas e com previsão de esgotamento no futuro, portanto, a busca por fontes de energia alternativas e de preferência renováveis é de suma importância. Neste contexto, os óleos vegetais aparecem como opção para substituição ao óleo diesel em motores de ignição por compressão (MENEZES; ANTUNES, 2005).

Dentre as oleaginosas, a mamoneira se destaca em função da ampla distribuição geográfica, ocorrendo de forma frequente nas diversas regiões do Brasil devido às características de xerofilismo, heliofilismo, além de boa adaptação a distintas condições de solo e manejo. Possui hábito arbustivo, com variadas colorações de caule, folhas e racemos (cachos) e em geral, os frutos possuem espinhos que, em alguns casos, são inermes, e as sementes apresentam com diferentes tamanhos, formatos e cores. É uma cultura rústica, de crescimento rápido, elevada produção e considerável teor de óleo em suas sementes (AZEVÊDO; LIMA, 2001).

A escassez de recursos hídricos nas regiões áridas e semiáridas envolvem aspectos quantitativos e qualitativos, principalmente no que diz respeito à presença de sais nestes recursos, causando restrições de uso para o consumo humano, animal e irrigação (MEDEIROS et al., 2003). A escassez do estoque de água de qualidade para a irrigação e a concorrência de outros usuários, faz com que os agricultores tenham dificuldade para acessar este recurso natural (DEGHANISANIJ; YAMAMOTO; INOURE, 2004) e assim procuram usar água de qualidade inferior, em geral salinas. Conforme Rhoades, Kandiah e Mashali (2000), o uso de água salina na agricultura deve ser considerado como uma alternativa importante na utilização dos recursos naturais escassos, como a água, principalmente nas regiões áridas, como por exemplo no Nordeste Brasileiro.

Os efeitos adversos dos sais dissolvidos nas águas ou nos solos, na maioria dos casos, refletemse na inibição e desuniformidade do crescimento, declínio na capacidade produtiva e na qualidade dos produtos obtidos das plantas cultivadas (AYERS; WESTCOT, 1999; ARRUDA et al., 2002) devido aos efeitos diretos sobre o potencial osmótico, desbalanceamento nutricional e efeito tóxico de íons, principalmente o cloro e o sódio (LACERDA et al., 2003).

Segundo Chaves, Gheyi e Ribeiro (2011), a adubação é uma das principais tecnologias usadas para aumentar a produtividade e a rentabilidade das culturas, sendo o nitrogênio, um dos principais macronutrientes responsáveis por esse incremento, por fazer parte da estrutura da planta, sendo componente de aminoácidos, proteínas, enzimas, clorofila, dentre outras moléculas, estando diretamente relacionado as características ligadas ao crescimento da planta. Kafkafi (1984) cita que entre os diversos efeitos da salinidade sobre as plantas, existem evidências de competição na absorção entre nitrato e cloreto, de modo que um aumento 
na concentração de nitrato na zona radicular pode reduzir a absorção de cloreto pela planta.

O trabalho foi realizado com o objetivo de avaliar diferentes níveis de salinidade da água de irrigação e doses de nitrogênio sobre o crescimento e a produção de mamoneira.

\section{Material e Métodos}

O estudo foi conduzido entre outubro de 2010 e fevereiro de 2011, em lisímetros tipo vasos sob condições de campo no Centro de Ciências e Tecnologia Agroalimentar da Universidade Federal de Campina Grande, Pombal, PB, situada a $6^{\circ} 48^{\prime}$ $16^{\prime \prime}$ de latitude sul, $37^{\circ} 49^{\prime} 15^{\prime \prime}$ de longitude oeste e altitude média de $144 \mathrm{~m}$.

O delineamento estatístico utilizado foi em blocos inteiramente casualizados em esquema fatorial $5 \times 5$, com três repetições, sendo o primeiro fator constituído dos diferentes níveis de condutividades elétricas da água de irrigação ( $\mathrm{S} 1,0,4 ; \mathrm{S} 2,1,4$; S3, 2,4; S4, 3,4 e S5, 4,4 dS m ${ }^{-1}$ ) e o segundo de doses de adubação nitrogenada [N1, 50; N2, 75; N3,100; N4, 125; e N5,150\% da indicação de adubação nitrogenada para ensaios, conforme Novais, Neves e Barros (1991)]. As unidades experimentais foram dispostas em fileira simples espaçadas de $0,9 \mathrm{~m}$ entre fileiras e $0,7 \mathrm{~m}$ entre plantas.

Os diferentes níveis de salinidade da água, foram obtidos a partir da adição do cloreto de sódio $(\mathrm{NaCl})$ em água proveniente do sistema de abastecimento local, cuja quantidade (C) foi determinada com base na equação de Richards (1954), sendo C (mg L-1) $=640 \times \mathrm{CEa}\left(\mathrm{dS} \mathrm{m}{ }^{-1}\right)$, em que a CEa representa o valor desejado da condutividade elétrica da água. As respectivas soluções salinas foram acondicionadas em tonéis plásticos de $200 \mathrm{~L}$ de capacidade.

A cultivar de mamoneira utilizada foi a 'BRS Energia'. De acordo com Milani (2010) este material genético possui ciclo de 120 a 150 dias, frutos semi- indeiscentes, teor de óleo nas sementes em média de $48 \%$ e produtividade aproximada de $1.800 \mathrm{~kg} \mathrm{ha}^{-1}$.

Utilizaram-se, no estudo, lisímetros de drenagem de $100 \mathrm{~L}$ de capacidade, preenchidos com $2,0 \mathrm{~kg}$ de brita ( $\mathrm{n}^{\mathrm{o}}$ zero) a qual cobria a base do lisímetro seguida de 107,8 kg de solo (tipo areia franca) não salino e não sódico, proveniente do Município de Pombal, PB. As características físico-químicas (Tabela 1) foram determinadas no Laboratório de Solos e Nutrição de Plantas do Centro de Ciências e Tecnologia Agroalimentar da Universidade Federal de Campina Grande, segundo metodologia proposta pela Embrapa (1997). Na parte inferior de cada lisímetro existiam furos para permitir a drenagem e abaixo dos mesmos um microtubo (1 cm de diâmetro) conectando sua base a uma garrafa plástica (2 L de capacidade) para acompanhamento do volume drenado e consumo de água pela cultura.

Realizou-se adubação básica aplicando-se 162,5 $\mathrm{g}$ de superfosfato simples, $12 \mathrm{~g}$ de sulfato de potássio e $2.200 \mathrm{~g}$ (equivalente a $2 \%$ ) de vermicomposto por vaso visando melhorar as propriedades físicas, químicas e biológicas do solo, de forma a aumentar a capacidade de retenção e infiltração de água no solo. Após o acondicionamento do substrato nos lisímetros foram aplicados os tratamentos com diferentes soluções salinas até ser atingida a capacidade máxima de retenção de água, conforme o método de saturação por capilaridade, seguida por drenagem livre.

A semeadura da mamona foi realizada em 28 de outubro de 2010, com 10 sementes por vaso a $2 \mathrm{~cm}$ de profundidade, distribuídas de forma equidistante. A emergência das plântulas teve inicio no sexto dia após a semeadura (DAS) e continuou até o décimo terceiro dia. Aos 14 DAS realizou-se o primeiro desbaste, deixando-se quatro plantas de melhor vigor por vaso e aos 21, 35 e 46 DAS, foram realizados novos desbastes a fim de manter uma única planta por vaso. 
Tabela 1. Características físicas e químicas do solo utilizado na pesquisa.

\begin{tabular}{|c|c|}
\hline Característica & Valor \\
\hline Classificação textural & Areia Franca \\
\hline Densidade aparente $-\mathrm{kg} \mathrm{dm}^{-3}$ & 1,31 \\
\hline Porosidade $-\mathrm{m}^{3}$ & 48,22 \\
\hline \multicolumn{2}{|l|}{ Complexo sortivo $\left(\mathrm{cmol}_{\mathrm{c}} \mathrm{kg}^{-1}\right)$} \\
\hline Cálcio $\left(\mathrm{Ca}^{2+}\right)$ & 7,50 \\
\hline Magnésio $\left(\mathrm{Mg}^{2+}\right)$ & 5,15 \\
\hline Sódio $\left(\mathrm{Na}^{+}\right)$ & 0,29 \\
\hline Potássio $\left(\mathrm{K}^{+}\right)$ & 0,29 \\
\hline \multicolumn{2}{|l|}{ Extrato de saturação } \\
\hline $\mathrm{pH}_{\mathrm{ps}}$ & 7,33 \\
\hline $\mathrm{CE}_{\mathrm{es}}^{\mathrm{ps}}-\mathrm{dS} \mathrm{m^{-1 }}$ & 0,53 \\
\hline Cloro $\left(\mathrm{Cl}^{-}\right)\left(\mathrm{mmol}_{\mathrm{c}} \mathrm{L}^{-1}\right)$ & 3,75 \\
\hline Carbonato $\left(\mathrm{CO}_{3}{ }^{2-}\right)\left(\mathrm{mmol}_{\mathrm{c}} \mathrm{L}^{-1}\right)$ & 0,00 \\
\hline Bicarbonato $\left(\mathrm{HCO}_{3}^{-}\right)\left(\mathrm{mmol}_{\mathrm{c}} \mathrm{L}^{-1}\right)$ & 2,00 \\
\hline Sulfato $\left(\mathrm{SO}_{4}^{2-}\right)\left(\mathrm{mmol}_{\mathrm{c}} \mathrm{L}^{-1}\right)$ & 0,89 \\
\hline Cálcio $\left(\mathrm{Ca}^{2+}\right)\left(\mathrm{mmol}_{\mathrm{c}} \mathrm{L}^{-1}\right)$ & 1,87 \\
\hline Magnésio $\left(\mathrm{Mg}^{2+}\right)\left(\operatorname{mmol}_{\mathrm{c}} \mathrm{L}^{-1}\right)$ & 1,25 \\
\hline Sódio $\left(\mathrm{Na}^{+}\right)\left(\mathrm{mmol} \mathrm{L}^{-1}\right)^{\mathrm{c}}$ & 2,51 \\
\hline Potássio $\left(\mathrm{K}^{+}\right)\left(\mathrm{mmol} \mathrm{L}^{-1}\right)$ & 0,49 \\
\hline
\end{tabular}

Fonte: Laboratório de Solos e Nutrição de Plantas/CCTA/UFCG, Pombal, PB, 2011.

A adubação nitrogenada foi aplicada $1 / 3 \mathrm{em}$ fundação e os $2 / 3$ restante, parcelada em quatro vezes, e aplicada via fertirrigação em intervalos de onze dias a partir de 24 DAS, sendo aplicados no tratamento $\mathrm{N}_{3} 16,67 \mathrm{~g}$ de fosfato monoamônio (MAP) e 4,44 g de uréia por vaso. A quantidade de fertilizante aplicado nos demais tratamentos foi calculada conforme $\mathrm{N}_{3}[(100 \%$ da dose recomendada conforme Novais, Neves e Barros (1991)]. A recomendação de adubação leva em consideração a fertilidade do solo e a produtividade esperada.

Aos 29 e 37 DAS, ou seja, período inicial da emissão das flores, descrito por Moshkin (1986) como estádio $\mathrm{R} 9$, foram realizadas adubações foliares com Albatroz $\left(\mathrm{N}-10 \%, \mathrm{P}_{2} \mathrm{O}_{5}-52 \%, \mathrm{~K}_{2} \mathrm{O}\right.$ $-10 \%, \mathrm{Ca}-0,1 \%, \mathrm{Zn}-0,02 \%, \mathrm{~B}-0,02 \%, \mathrm{Fe}-$ $0,15 \%, \mathrm{Mn}-0,1 \%, \mathrm{Cu}-0,02 \%$ e $\mathrm{Mo}-0,005 \%$ ) na proporção de $1 \mathrm{~g}$ do adubo para $1 \mathrm{~L}$ de água, aplicando-se $5 \mathrm{~L}$, distribuídos nas plantas, com auxilio de um pulverizador costal.
A irrigação com as diferentes soluções salinas foi realizada diariamente a partir da semeadura, sempre ao final da tarde. O critério de reposição da umidade foi com base no balanço de água na zona radicular (volume de água aplicado menos o volume drenado na irrigação anterior), acrescido de fração de lixiviação 0,01 .

Durante o período experimental foram realizados os seguintes tratos culturais: eliminação manual de plantas daninhas, tutoramento das plantas, escarificação superficial do solo antes de cada irrigação, além de pulverizações com Abamectina, a cada 30 dias, visando o controle preventivo de pragas.

Para análise do efeito dos tratamentos foram avaliados aos 35 e 120 dias após a semeadura, o número de folhas (NF), a altura de planta (AP) e o diâmetro do caule (DC). Aos 120 DAS avaliou-se a fitomassa seca de caule (FSC) e de folhas (FSF); visando avaliar a produção, determinou-se o número de frutos no racemo primário (NFrutRP). 
A altura foi definida mensurando-se a distância entre o colo da planta e a inserção do racemo primário; na quantificação do número de folhas, foram consideradas as folhas com no mínimo $50 \%$ de sua área fotossinteticamente ativa e comprimento mínimo de $3 \mathrm{~cm}$; o diâmetro do caule foi determinado a $5 \mathrm{~cm}$ do colo das plantas, utilizando-se paquímetro digital; para avaliação da fitomassa seca das plantas (FSC e FSF), realizouse a colheita cortando a haste de cada planta rente ao solo e posteriormente colocou-se para secar em estufa com ventilação forçada de ar, a $65^{\circ} \mathrm{C}$, até a obtenção de massa constante.

A colheita do racemo primário foi realizada manualmente e teve início aos 72 DAS, quando a planta se encontrava no estádio fenológico R12 (MOSHKIN, 1986), ou seja, quando 90\% dos frutos atingiram sua maturação fisiológica; na sequência, os frutos foram separados e identificados conforme tratamento e repetição. Após a colheita, os frutos foram expostos ao sol por um período de 48 horas e em seguida, determinou-se o número de frutos no racemo primário.

Os dados obtidos foram avaliados mediante análise de variância pelo teste ' $\mathrm{F}$ ' ao nível de 0,05 e 0,01 de probabilidade e nos casos de significância, realizou-se análise de regressão polinomial linear, quadrática e cúbica utilizando-se o software estatístico SISVAR-ESAL (FERREIRA, 2003). Os dados das variáveis número de folhas, fitomassa seca do caule e de folhas aos 120 DAS, assim como o número de frutos no racemo primário foram transformados em $\sqrt{X}$.

\section{Resultados e Discussão}

Conforme análise de variância (Tabelas 2 e 3 ) observa-se não haver efeito significativo na interação entre os fatores estudados (salinidade da água de irrigação - S e doses de adubação nitrogenada $-\mathrm{N}$ ) para as variáveis número de folhas (NF) e altura de planta (AP) aos 35 e 120 DAS, assim como para diâmetro de caule (DC) aos 35 DAS, fitomassa seca de caule (FSC) e de folhas (FSF) aos 120 DAS e número de frutos no racemo primário (NFrutRP), denotando comportamento semelhante das doses de $\mathrm{N}$ dentro da salinidade da água. Entretanto, constatase haver efeito significativo $(p<0,05)$ na interação entre os fatores ( $\mathrm{S} \times \mathrm{N}$ ) para a variável DC aos 120 DAS. Oliveira et al. (2006) estudando os efeitos da irrigação com água de diferentes salinidades e teores de esterco bovino no crescimento inicial da mamoneira observaram não haver interação entre os fatores.

Segundo a análise de variância (Tabela 2), os níveis de condutividade elétrica da água de irrigação (CEa) apresentaram efeitos significativos $(\mathrm{p}<0,01)$ sobre o número de folhas (NF) da mamoneira aos 35 e 120 DAS. Analisando as equações de regressão (Figura 1) verifica-se comportamento linear, com decréscimo no NF de 5,28 e 13,24\% por aumento unitário da CEa, ou seja, redução de 21,12 e 52,97\% no NF quando se comparam os dados de $\mathrm{S}_{5}$ em relação a $S_{1}$ respectivamente aos 35 e 120 DAS. Silva et al. (2008) em estudos com genótipos de mamoneira verificou aos 80 DAS redução linear no número de folhas da cv. BRS Energia, com decréscimos na ordem de 7,5\% por incremento unitário da salinidade da água de irrigação e aos 100 DAS às plantas submetidas à CEa de $6,7 \mathrm{dS} \mathrm{m}^{-1}$ tiveram redução no NF de $72,1 \%$ em comparação as irrigadas com água de $0,7 \mathrm{dS} \mathrm{m}^{-1}$. Cavalcanti et al. (2005) estudando a influência da salinidade na germinação e no crescimento da mamoneira BRS 149 - Nordestina, verificaram que, a partir do nível de salinidade de $1,78 \mathrm{dS} \mathrm{m}^{-1}$, o número de folhas reduz-se, linearmente, na ordem de $2,95 \%$ para cada incremento unitário da CEa. Segundo Oliveira et al. (2010), em condições de estresse salino, é comum ocorrerem alterações morfológicas e anatômicas nas plantas, que refletem na redução da transpiração como alternativa para manter a baixa absorção de água salina; e dentre essas adaptações, está a redução do número de folhas. 
Tabela 2. Teste F para número de folha (NF), altura de planta (AP) e diâmetro de caule (DC) aos 35 e 120 dias após a semeadura (DAS) da mamona, cultivada sob diferentes níveis de salinidade da água de irrigação e doses de nitrogênio.

\begin{tabular}{lcccccc}
\hline \multirow{2}{*}{ Fonte de Variação } & \multicolumn{7}{c}{ Teste F } \\
\cline { 2 - 7 } & \multicolumn{2}{c}{ NF } & \multicolumn{2}{c}{ AP (cm) } & \multicolumn{2}{c}{ DC (mm) } \\
& 35 DAS & 120 DAS & 35 DAS & 120 DAS & 35 DAS & 120 DAS \\
\hline Níveis salino (S) & $* *$ & $* *$ & $* *$ & $* *$ & $* *$ & $* *$ \\
Reg. Linear & $* *$ & $* *$ & $* *$ & $* *$ & $* *$ & $* *$ \\
Reg. Quadrática & $\mathrm{ns}$ & $\mathrm{ns}$ & $*$ & $\mathrm{~ns}$ & $\mathrm{~ns}$ & $\mathrm{~ns}$ \\
Reg. Cúbica & $\mathrm{ns}$ & $\mathrm{ns}$ & $\mathrm{ns}$ & $\mathrm{ns}$ & $\mathrm{ns}$ & $\mathrm{ns}$ \\
Doses nitrogênio (N) & $\mathrm{ns}$ & $\mathrm{ns}$ & $*$ & $\mathrm{~ns}$ & $\mathrm{~ns}$ & $*$ \\
Reg. Linear & $\mathrm{ns}$ & $\mathrm{ns}$ & $\mathrm{ns}$ & $\mathrm{ns}$ & $\mathrm{ns}$ & $* *$ \\
Reg. Quadrática & $\mathrm{ns}$ & $\mathrm{ns}$ & $* *$ & $\mathrm{~ns}$ & $\mathrm{~ns}$ & $\mathrm{~ns}$ \\
Reg. Cúbica & $\mathrm{ns}$ & $\mathrm{ns}$ & $\mathrm{ns}$ & $\mathrm{ns}$ & $\mathrm{ns}$ & $\mathrm{ns}$ \\
Interação (S x N) & $\mathrm{ns}$ & $\mathrm{ns}$ & $\mathrm{ns}$ & $\mathrm{ns}$ & $\mathrm{ns}$ & $*$ \\
Bloco & $\mathrm{ns}$ & $\mathrm{ns}$ & $* *$ & $\mathrm{~ns}$ & $* *$ & $\mathrm{~ns}$ \\
CV (\%) & 16,64 & 29,22 & 10,03 & 8,44 & 7,12 & 8,34 \\
\hline
\end{tabular}

ns, **, * respectivamente não significativo, significativo a $\mathrm{p}<0,01$ e p $<0,05 ;{ }^{1}$ análise estatística realizada após transformação de dados em $\sqrt{X}$

Fonte: Elaboração dos autores.

O fator adubação nitrogenada não promoveu efeito significativo sobre o número de folhas em nenhuma época de avaliação (Tabela 2). Verificouse neste estudo que as plantas sob diferentes doses de $\mathrm{N}$ produziram em média 25 folhas aos 120 DAS, resultado este superior aos encontrados por Oliveira Filho et al. (2010) com a mesma cultivar, no entanto, em condição de campo, onde as plantas adubadas com $70 \mathrm{~kg} \mathrm{ha}^{-1}$ de $\mathrm{P}_{2} \mathrm{O}_{5}$ e $70 \mathrm{~kg} \mathrm{ha}^{-1}$ de $\mathrm{N}$ apresentaram em média 22,9 folhas e as plantas não adubadas produziram um NF médio 19,5. Freire et al. (2010) trabalhando com doses de $\mathrm{N}$ fornecidas através da torta de mamona em quantidades que variavam de 50 a $200 \mathrm{~kg} \mathrm{ha}^{-1}$ sobre o crescimento inicial do pinhão manso constataram não haver efeito significativo das doses de $\mathrm{N}$ sobre o número de folhas da cultura no período de 42 a 168 dias após o transplantio.

Em relação à altura de plantas (AP) constatou-se efeito $(\mathrm{p}<0,01)$ da salinidade de água de irrigação aos 35 e 120 DAS e da adubação nitrogenada ( $p$ $<0,05$ ) apenas aos 35 DAS (Tabela 2). De acordo com as equações de regressão (Figura 2A), houve efeito linear e decrescente, com redução da AP de 5,05 e $6,01 \%$ por aumento unitário da $\mathrm{CEa}$, ou seja decréscimo de 20,23 e 24,01\% para AP aos 35 e 120 DAS, respectivamente, nas plantas irrigadas com água de 4,4 $\mathrm{dS} \mathrm{m}^{-1}$ em relação a testemunha $\left(0,4 \mathrm{dS} \mathrm{m}^{-1}\right)$. Corroborando com o presente estudo, Cavalcanti et al. (2005) estudando o comportamento da mamoneira irrigada com água de condutividade elétrica variando entre 0,7 e 4,7 dS m$~^{-1}$, observaram redução da altura de planta de 5,85\% por aumento unitário da CEa para a cultivar BRS Nordestina. Severino, Vale e Beltrão (2006) trabalhando com outra oleaginosa, o pinhão manso, em condição de ambiente protegido sob diferentes níveis de $\mathrm{CEa}$ $\left(0,6\right.$ a 4,2 dS m $\left.{ }^{-1}\right)$ encontraram aos 30 DAS redução da AP de 7,85\% por aumento unitário da CEa. 
Figura 1. Número de folhas da mamoneira em função da condutividade elétrica da água de irrigação (CEa) aos 35 e 120 dias após semeadura (DAS).

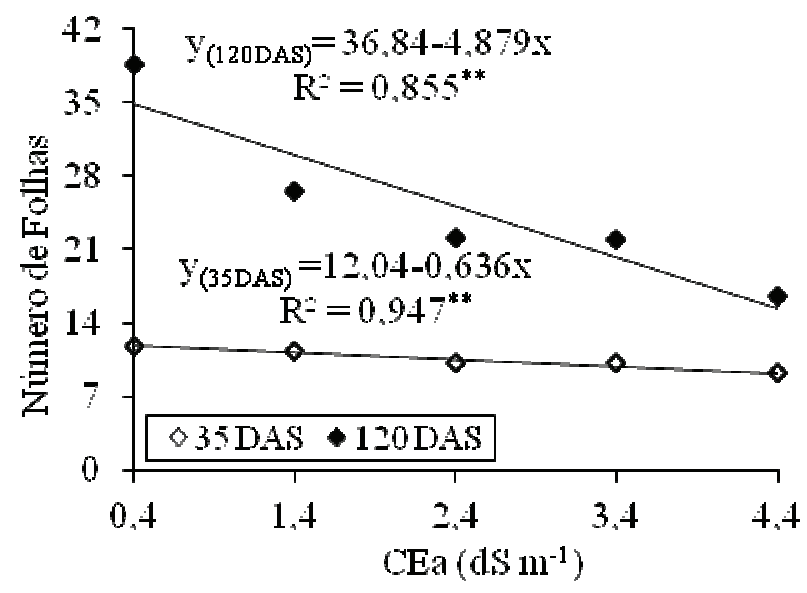

Fonte: Elaboração dos autores.

O efeito osmótico tem sido a causa maior da redução do crescimento das plantas, associado à toxidez de íons devido à absorção excessiva de sódio e cloro e ao desequilíbrio nutricional causado pelos distúrbios na absorção e/ou distribuição dos nutrientes (YAHYA, 1998). Segundo Flowers (2004) as plantas tendem a fechar os estômatos para reduzir as perdas de água por transpiração, resultando em uma menor taxa fotossintética, e contribuindo para redução do crescimento das espécies sob tal estresse.

Em relação ao fator dose de nitrogênio o modelo ao qual os dados se ajustaram em termos de altura de plantas aos 35 DAS, foi o quadrático (Figura 2B) onde nota-se resposta positiva no fornecimento da adubação nitrogenada até a dose de $95 \%$, obtendo com este valor, a máxima altura estimada das plantas $(48,746 \mathrm{~cm})$. Constata-se ainda na Figura 2B que níveis de $\mathrm{N}$ variando entre 74 a $115 \%$ proporcionaram alturas de planta superior a $48 \mathrm{~cm}$, ou seja, valores esses, próximos a maior AP encontrada. Infere-se conforme resultados que a menor (50\%) e a maior (150\%) dose de adubação nitrogenada foram prejudiciais em termos de crescimento em altura. Rodrigues et al. (2010) estudando os efeitos da adubação nitrogenada na produção de mudas de mamoneira, verificaram também que doses elevadas de $\mathrm{N}$ proporcionaram menor altura de plantas. Conforme Oliveira et al. (2009), elevados teores de esterco, ou seja, adubo fonte de adubação nitrogenada podem proporcionar desbalanço entre nutrientes no solo e, em consequência, redução no crescimento, desenvolvimento e produção da cultura.

$\mathrm{O}$ fator salinidade da água de irrigação afetou $(\mathrm{p}<$ 0,01) o diâmetro caulinar (DC) aos 35 DAS (Tabela 2). Conforme a equação de regressão (Figura $3 \mathrm{~A}$ ) o modelo linear indica decréscimo de $3,85 \%$ no DC por aumento unitário da $\mathrm{CEa}$, ou seja, redução de $15,40 \%$ no diâmetro do caule das plantas irrigadas com água de $4,4 \mathrm{dS} \mathrm{m}^{-1}$ em relação as submetidas a 0,4 $\mathrm{dS} \mathrm{m}{ }^{-1}$. Silva et al. (2008) conduzindo experimento em ambiente protegido com cultivares de mamona também verificaram efeito linear e decrescente da CEa sobre o DC, constatando redução de 9,1 e 9,8\% por incremento unitário da CEa respectivamente aos 80 e 100 DAS. Nery et al. (2009), estudando os efeitos de salinidade em pinhão-manso em casa de vegetação, verificaram redução no diâmetro das plantas de 7,35\%, por aumento unitário da CEa. Segundo Rhoades, Kandiah e Mashali (2000), o excesso de sais na zona radicular das plantas exerce efeitos nocivos no crescimento. A hipótese que 
melhor explica este fato é a de que a salinidade excessiva reduz o crescimento e o desenvolvimento e causa até a morte de plantas em virtude do maior efeito osmótico externo à raiz e restrição ao fluxo de água do solo para as plantas, necessário para sobreviverem e produzirem em condições de estresse salino.

Figura 2. Altura de planta da mamoneira em função da condutividade elétrica da água de irrigação - CEa aos 35 e 120 dias após semeadura - DAS (A) e das doses de nitrogênio aos 35 DAS (B).
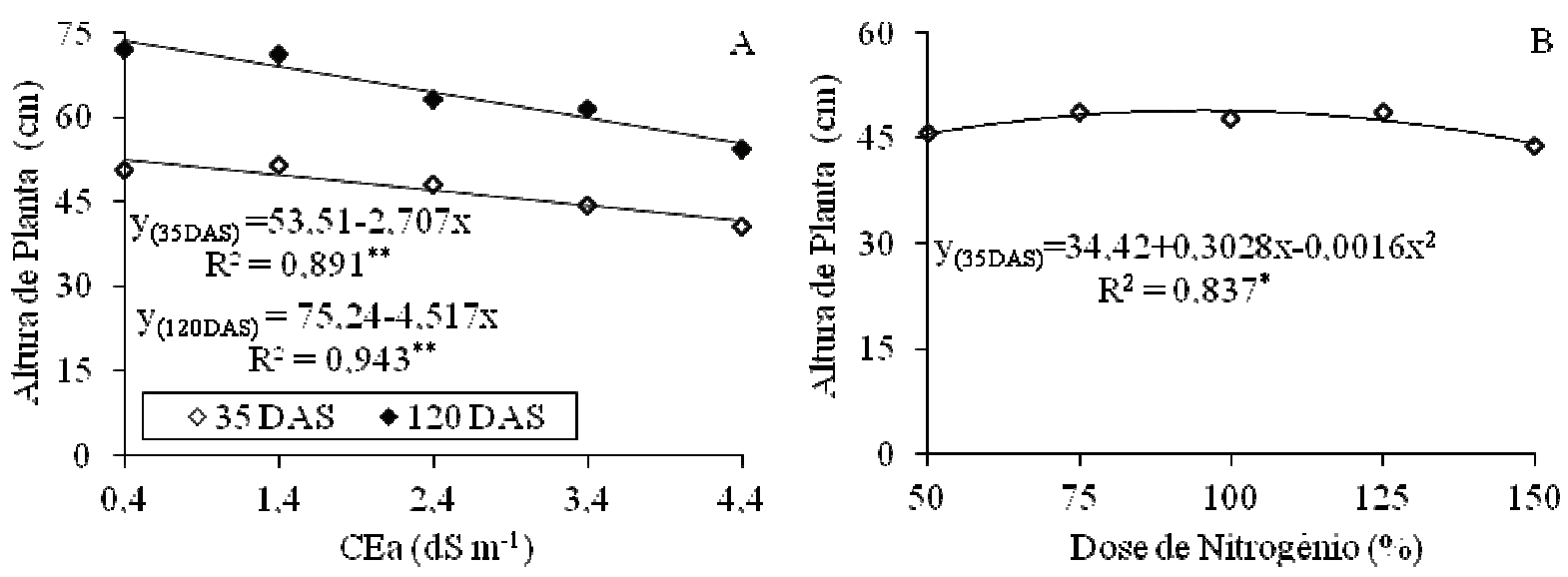

Fonte: Elaboração dos autores.

Figura 3. Diâmetro de caule da mamoneira em função da condutividade elétrica da água de irrigação - CEa aos 35 DAS (A) e em função da CEa e das doses de adubação nitrogenada - N aos 120 DAS (B).
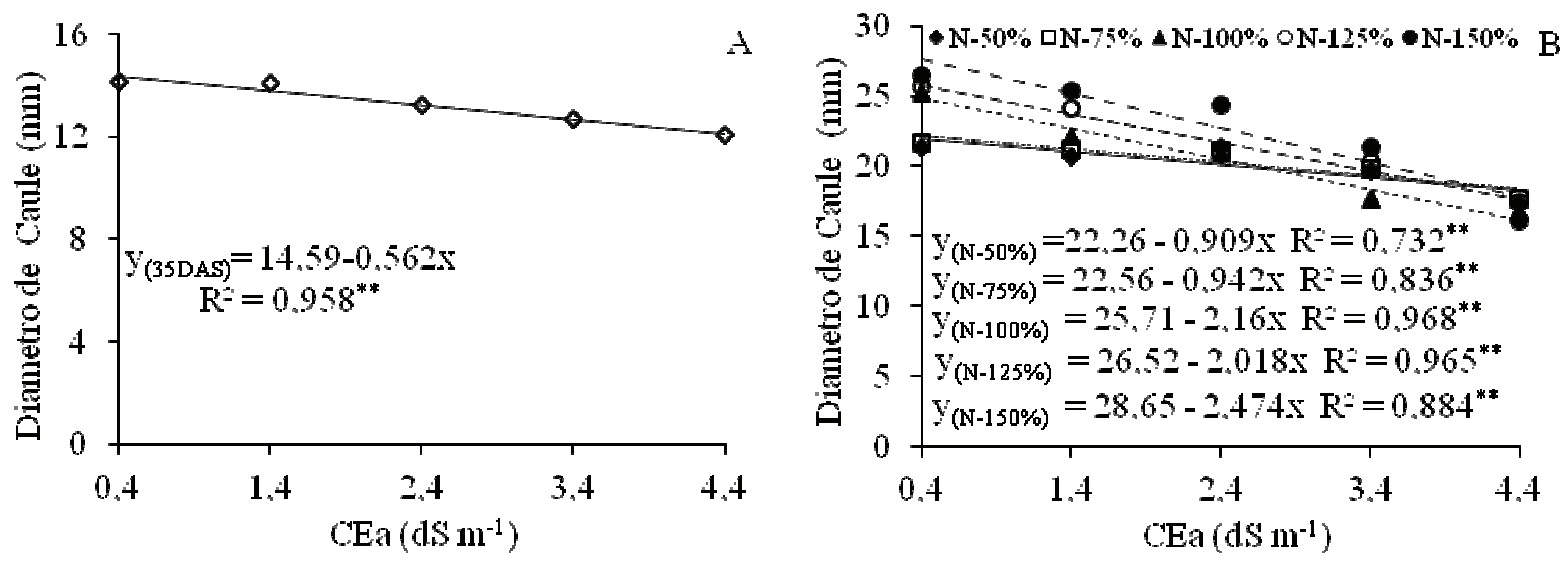

Fonte: Elaboração dos autores.

Verificou-se aos 120 DAS (Tabela 2), efeito significativo para interação entre salinidade da água de irrigação e doses de nitrogênio sobre o diâmetro do caule. De acordo com as equações de regressão (Figura 3B) houve efeito linear decrescente no DC das plantas adubadas com 50, 75, 100, 125 e $150 \%$ de $\mathrm{N}$ na ordem de 4,$08 ; 4,17 ; 8,40 ; 7,60$ e $8,63 \%$ respectivamente, por aumento unitário da $\mathrm{CEa}$ ou seja, redução de 3,$6 ; 3,7 ; 8,6 ; 8,1$ e $9,9 \mathrm{~mm}$ no DC das plantas irrigadas com CEa de $4,4 \mathrm{dS} \mathrm{m}^{-1}$ 
em relação as sob $\mathrm{CEa}$ de $0,4 \mathrm{dS} \mathrm{m}^{-1}$. Analisando isoladamente as plantas adubadas submetidas às distintas doses de N (Figura 3B) vê-se que houve redução crescente do DC em função do incremento da $\mathrm{CEa}$, entretanto, constata-se que a medida em que houve aumento na dose de $\mathrm{N}$, independente do nível salino, ocorreu maior desenvolvimento do diâmetro do caule das plantas. A fertilização nitrogenada além de promover o crescimento das plantas pode também reduzir o efeito da salinidade sobre os vegetais (FLORES et al., 2001) devido a acumulação desses solutos elevar a capacidade de ajustamento osmótico das plantas à salinidade, e aumenta a resistência das culturas ao estresse hídrico e salino (SILVA et al., 2008).
Analisando os resultados das variáveis, número de folhas, altura de plantas e diâmetro de caule da mamoneira aos 35 e 120 DAS, nota-se que os efeitos da salinidade foram intensificados com o tempo, tendo as variáveis atingindo os maiores decréscimos aos 120 DAS (Figura 1A, 2A e 3A). Destas variáveis de crescimento, o NF foi a mais afetada pelo incremento de salinidade da água de irrigação, assim como, em função do tempo de exposição ao estresse salino.

Conforme os resultados do teste F (Tabela 3) vê-se a ocorrência de efeito significativo dos fatores isolados (condutividade elétrica da água de irrigação e doses de nitrogênio) sobre as variáveis, fitomassa seca de folhas (FSF) e de caule (FSC) aos 120 dias após a semeadura, e para número de frutos no racemo primário (NFrutRP).

Tabela 3. Teste F para fitomassa seca do caule (FSC) e de folhas (FSF) aos 120 dias após a semeadura (DAS) e número de frutos no racemo primário (NFruRP) da mamona, cultivada sob diferentes níveis de salinidade da água de irrigação e doses de nitrogênio.

\begin{tabular}{lccc}
\hline \multirow{2}{*}{ Fonte de Variação } & & Teste F & \\
\cline { 2 - 4 } & $\mathrm{FSF}^{1}$ & $\mathrm{FSC}^{1}$ & $* *$ \\
\hline Níveis salino (S) & $* *$ & $* *$ & $* *$ \\
Reg. Linear & $* *$ & $\mathrm{~ns}$ & $*$ \\
Reg. Quadrática & $\mathrm{ns}$ & $* *$ & $\mathrm{~ns}$ \\
Reg. Cúbica & $*$ & $* *$ & $*$ \\
Doses nitrogênio (N) & $*$ & $* *$ & $\mathrm{~ns}$ \\
Reg. Linear & $* *$ & $\mathrm{~ns}$ & $*$ \\
Reg. Quadrática & $\mathrm{ns}$ & $\mathrm{ns}$ & $\mathrm{ns}$ \\
Reg. Cúbica & $\mathrm{ns}$ & $\mathrm{ns}$ & $\mathrm{ns}$ \\
Interação (S x N) & $\mathrm{ns}$ & $\mathrm{ns}$ & $\mathrm{ns}$ \\
Bloco & $\mathrm{ns}$ & 12,68 & 17,56 \\
CV (\%) & 15,65 & \multicolumn{2}{c}{} \\
\hline
\end{tabular}

ns, ${ }^{* *},{ }^{*}$ respectivamente não significativo, significativo a $\mathrm{p}<0,01$ e $\mathrm{p}<0,05 ;{ }^{1}$ análise estatística realizada após transformação de dados em $\sqrt{X}$

Fonte: Elaboração dos autores.

A fitomassa seca de folhas (FSF) foi afetada ( $\mathrm{p}$ $<0,01$ ) pela CEa (Tabela 3). Por meio da equação de regressão (Figura 4A) nota-se que o efeito foi linear decrescente ocorrendo redução na FSF da mamoneira de $17,51 \%$ por aumento unitário da $\mathrm{CEa}$, ou seja, redução de 21,08g (70,05\%) nas plantas submetidas ao nível salino $4,4 \mathrm{dS} \mathrm{m}^{-1}$ em relação a 0,4 dS m${ }^{-1}$. Para Leonardo et al. (2007), em condições salinas ocorre a redução da disponibilidade de água às plantas devido a redução do potencial total da água no solo, e assim, a salinidade impõe um maior gasto de energia nas plantas para a absorção da água 
e por consequente, ocorre diminuição na produção de matéria seca.

A adubação nitrogenada afetou $(p<0,05)$ a fitomassa seca das folhas aos 120 DAS (Tabela 3). De acordo com a equação de regressão (Figura 4B) o efeito foi linear, havendo incremento na FSF de $10,37 \%(5,95 \mathrm{~g})$ por aumento de $25 \%$ da dose de nitrogênio estudada. Foi alcançado com a maior dose de $\mathrm{N}(150 \%)$ uma fitomassa seca de folhas igual a $20 \mathrm{~g}$, ou seja, $41,49 \%$ maior que a dose de N de 50\%. Segundo Lacerda et al. (2003), o nitrogênio é de vital importância para as plantas, principalmente por ser componente de aminoácidos, proteínas, enzimas, RNA, DNA, ATP, clorofila dentre outras moléculas e sua deficiência geralmente provoca redução no crescimento, desenvolvimento e produção das plantas.

Figura 4. Fitomassa seca de folhas (FSF) da mamoneira, em função da condutividade elétrica da água de irrigaçãoCEa (A) e doses de nitrogênio (B) aos 120 dias após semeadura (DAS).
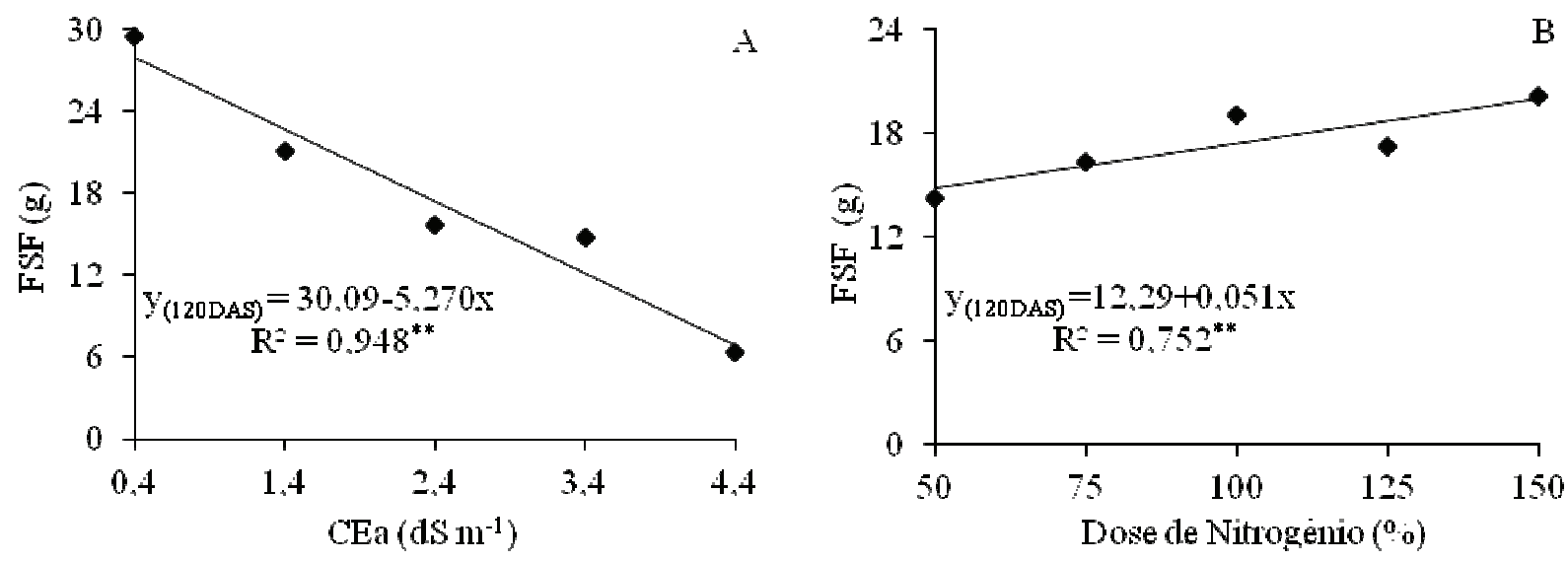

Fonte: Elaboração dos autores.

Analisando a equação de regressão (Figura 5A) referente à fitomassa seca do caule (FSC) aos 120 DAS, o modelo linear indica decréscimo de 12,93\% por aumento unitário da CEa ou seja, redução de $51,74 \%(24,52 \mathrm{~g})$ na FSC das plantas irrigadas com água de $4,4 \mathrm{dS} \mathrm{m} \mathrm{m}^{-1}$ em relação a testemunha.
Redução na produção de massa seca em função do estresse salino também foi relatada por Cavalcanti et al. (2005), onde verificaram aos 80 dias após a germinação da mamoneira BRS - 149 Nordestina cultivada sob diferentes níveis salinos ( 0,7 a 4,7 dS $\mathrm{m}^{-1}$ ), uma redução da fitomassa seca da parte aérea na ordem de $8,38 \%$ por aumento unitário da CEa. 
Figura 5. Fitomassa seca do caule (FSC) da mamoneira, em função da condutividade elétrica da água de irrigaçãoCEa (A) e doses de nitrogênio (B), aos 120 dias após semeadura (DAS).
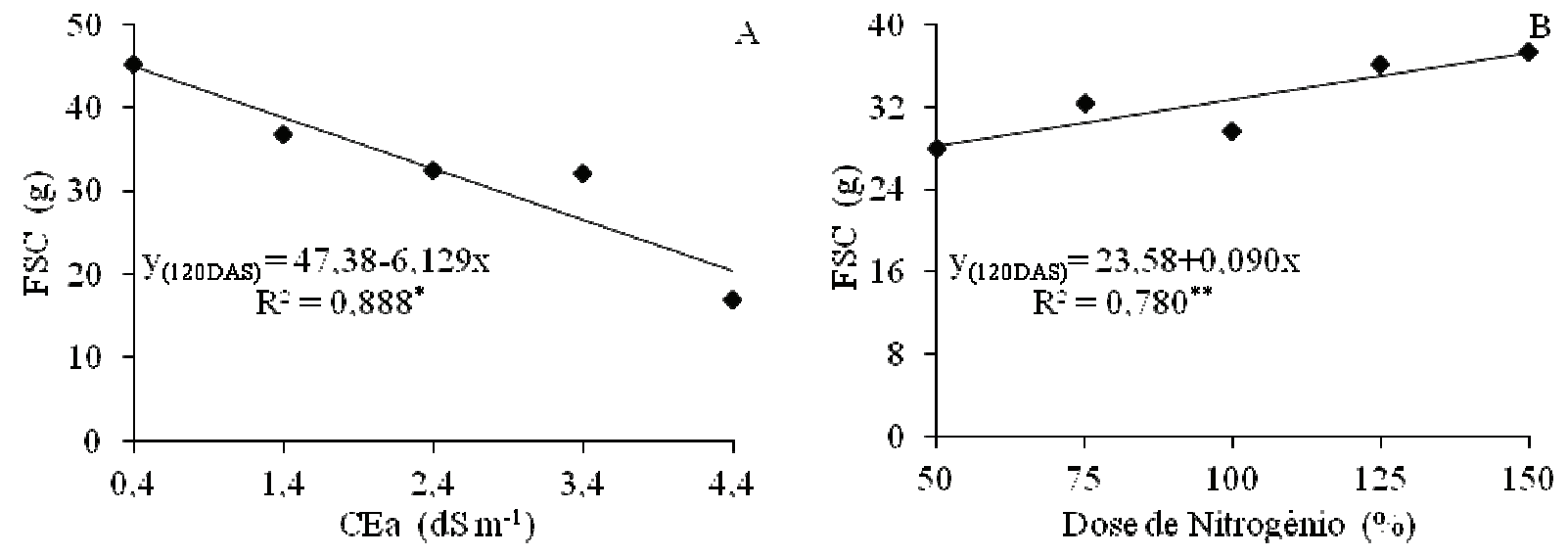

Fonte: Elaboração dos autores.

O aumento das doses de nitrogênio afetou $(\mathrm{p}<$ $0,01)$ a fitomassa seca de caule da mamoneira aos 120 DAS (Tabela 3). Pela equação de regressão (Figura 5B) vê-se que o modelo ao qual os dados melhor se ajustaram foi o linear, ocorrendo acréscimo na FSC de $11,45 \%$ por cada aumento de $25 \%$ nas doses de $\mathrm{N}$ estudada, ou seja, incremento de 45,80\% (9,00 g) na FSC das plantas submetidas a $150 \%$ de $\mathrm{N}$ em relação as que receberam $50 \%$ de $\mathrm{N}$.

A partir dos resultados de massa seca (FSF e FSC) das plantas de mamona, constata-se que o suprimento das plantas com nitrogênio proporcionou maior produção de matéria seca vegetal. Lavres Júnior et al. (2005) estudando a omissão de macronutrientes em mudas de mamoneira, concluíram que a produção total de matéria seca das plantas foi afetada pela deficiência dos macronutrientes, sendo o $\mathrm{N}$ o mais limitante.

De acordo com os resultados do teste F (Tabela 3), o número de frutos no racemo primário (NFruRP) foi afetado $(\mathrm{p}<0,01)$ em função dos diferentes níveis de salinidade da água de irrigação. O modelo de regressão linear (Figura 6A) reflete o comportamento decrescente, indicando declínio do NFrutRP de 16,28\% por aumento unitário da CEa. Comparando-se os valores obtidos no menor nível salino $\left(0,4 \mathrm{dS} \mathrm{m}^{-1}\right)$ com os encontrados nas plantas irrigadas com água de maior salinidade $(4,4 \mathrm{dS}$ $\mathrm{m}^{-1}$ ), verifica-se redução em cerca de $65,13 \%$ no número de frutos no racemo primário. Das variáveis estudadas, constata-se que a FSF e o NFrutRP foram as mais afetadas pelo incremento de salinidade da água de irrigação. Segundo Tester e Davenport (2003) a redução do potencial osmótico da solução do solo provocada pelo sal, dificulta a entrada de água nas células da planta e consequentemente prejudica o desempenho da cultura.

Em estudos com cultivares de mamoneira (BRS Paraguaçu e BRS Energia), Silva et al. (2008) observaram também, redução no número de frutos do racemo primário com o incremento da CEa verificando ainda que, as cultivares quando submetidas a irrigação com água de $4,7 \mathrm{dS} \mathrm{m} \mathrm{m}^{-1}$ produziram menos de 10 frutos no racemo primário e quando irrigadas com $\mathrm{CEa}$ de $6,7 \mathrm{dS} \mathrm{m}^{-1}$ não conseguiram frutificar. Estes autores ao compararem o NFrutRP das plantas da cv. BRS Energia irrigadas com CEa de 4,7 $\mathrm{dS} \mathrm{m}^{-1}$ com as sob $0,7 \mathrm{dS} \mathrm{m}^{-1}$ verificaram-se que esta foi, em média, $86 \%$ menos produtiva e a maior produção de frutos da $\mathrm{cv}$. foi obtida com CEa de $0,7 \mathrm{dS} \mathrm{m}^{-1}$ cujo valor médio foi 60 frutos por racemo. Esses valores são inferiores aos encontrados no presente trabalho, cuja produção 
do racemo primário variou de 80,5 a 26,7 frutos quando as plantas foram irrigadas respectivamente com CEa de 0,4 e 4,4 dS m $\mathrm{m}^{-1}$. Denota-se que esta diferença entre resultados de pesquisas com mesma cultivar possa ter ocorrido em função do experimento de Silva et al. (2008) ser realizado em ambiente protegido, e a polinização das flores tenha sido afetada; outrossim, na comparação entre os dois trabalhos, verifica-se haver uma diferença entre os níveis salinos de $0,3 \mathrm{dS} \mathrm{m}^{-1}$.

Souza Júnior et al. (2005) avaliando os efeitos de diferentes níveis de salinidade da água, variando de 2,0 a $9,5 \mathrm{dS} \mathrm{m}^{-1}$, constataram redução de $6,6 \%$ no número de capulho, por incremento unitário da condutividade elétrica da água de irrigação. Comparando com os dados obtidos neste trabalho denota-se ser a mamoneira mais sensível ao estresse salino que o algodão colorido.
Observa-se conforme equação de regressão das doses de nitrogênio sobre o NFrutRP (Figura 6B), resposta quadrática. $\mathrm{O}$ maior numero de frutos $(54,425)$ foi observado com a dosagem de $107 \%$ de N. Conforme equação (Figura 6B) as plantas quando submetidas a doses de $\mathrm{N}$ variando de 98 a $117 \%$ produziram em média NFrutRP igual a 54, e doses de adubação inferior e superior a este intervalo tiveram menor número de frutos. Segundo Fageria e Baligar (2006), o nitrogênio é o nutriente mais limitante para muitas culturas no mundo, e o seu uso eficiente é de extrema importância econômica para os sistemas de produção. Além do mais, a dinâmica natural do nitrogênio e a perda deste no sistema solo-planta criam um desafio único para seu correto manejo.

Figura 6. Número de frutos no racemo primário (NFruRP) da mamoneira, em função da condutividade elétrica da água de irrigação - CEa (A) e doses de nitrogênio (B).

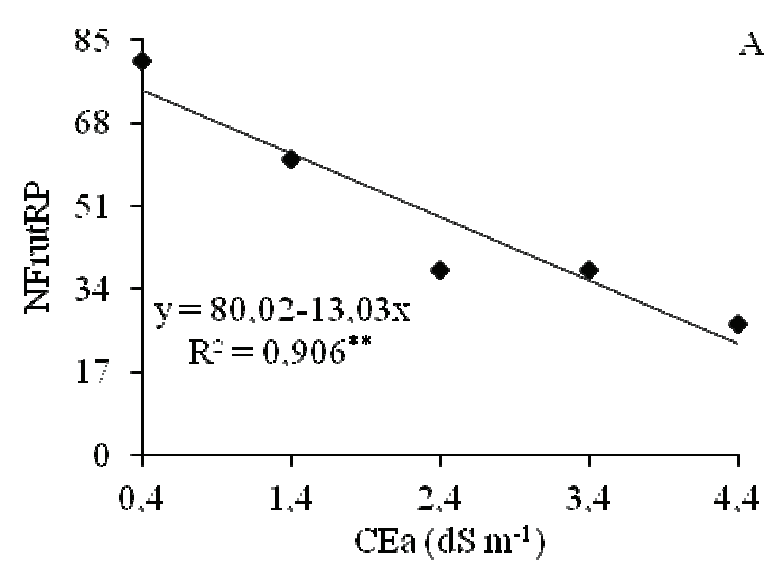

Fonte: Elaboração dos autores

\section{Conclusões}

1. O número de folhas, a altura de plantas, o diâmetro caulinar, a fitomassa seca de folhas e de caule, e o número de frutos no racemo primário da mamoneira cv. BRS Energia decrescem de forma linear a partir da salinidade da água de irrigação de $0,4 \mathrm{dS} \mathrm{m}^{-1}$.

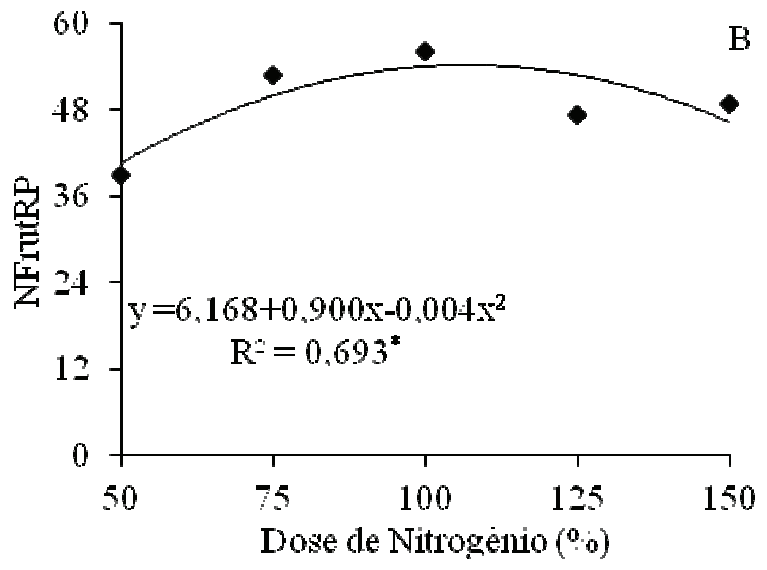

2. A fitomassa seca de folhas e a produção do racemo primário da mamoneira são as variáveis mais sensíveis ao estresse salino, ocorrendo respectivamente, redução de 17,51 e 16,28\% por aumento unitário da $\mathrm{CEa}$.

3. Doses crescentes de adubação nitrogenada proporcionaram aumento na fitomassa seca de 
folhas e de caule, e no número de frutos no racemo primário.

4. A aplicação de doses crescentes de nitrogênio reduziu o efeito da salinidade sobre o diâmetro de caule da mamoneira cv. BRS Energia.

\section{Agradecimentos}

Ao Conselho Nacional de Desenvolvimento Cientifico e Tecnológico - CNPq, pela concessão do auxílio financeiro (Projeto Universal) e bolsa PIBIC; e a Embrapa Algodão, pelo fornecimento das sementes de mamona.

\section{Referências}

ARRUDA, F. P. de; ANDRADE, A. P. de; SILVA, I. F. da; PEREIRA, I. E.; GUIMARÃES, M. A. M. Efeito do estresse hídrico na emissão/abscisão de estruturas reprodutivas do algodoeiro herbáceo cv. CNPA $7 \mathrm{H}$. Revista Brasileira de Engenharia Agrícola e Ambiental, Campina Grande, v. 6, n. 1, p. 21-27, 2002.

AYERS, R. S.; WESTCOT, D. W. A qualidade da água na agricultura. Campina Grande: Universidade Federal da Paraíba, 1999. 153 p. (Estudos FAO: Irrigação e drenagem, 29).

AZEVÊDO, D. M. P. de; LIMA, E. F. O Agronegócio da mamona no Brasil. Campina Grande: Embrapa Algodão, $2001.350 \mathrm{p}$.

CAVALCANTI, M. L. F.; FERNANDES, P. D.; GHEYI, H. R.; BARROS JÚNIOR, G.; SOARES, F. A. L.; SIQUEIRA, E. C. Tolerância da mamoneira BRS 149 à salinidade: germinação e características de crescimento. Revista Brasileira de Engenharia Agrícola e Ambiental, Campina Grande, v. 9, p. 57-61, 2005. Suplemento.

CHAVES, L. H. G.; GHEYI, H. R.; RIBEIRO, S. Consumo de água e eficiência do uso para cultivar de mamona Paraguaçu submetida à fertilização nitrogenada. Revista de Engenharia Ambiental, Espírito Santo do Pinhal, v. 8, n. 1, p. 126-133, 2011.

DEGHANISANIJ, H.; YAMAMOTO, T.; INOURE, M. Practical aspects of TDR for simultaneous measurements of water and solute in a dune sand field. Journal Japan Society Soil Physics, Japan, v. 98, n. 1, p. 21-30, 2004.
EMPRESA BRASILEIRA DE PESQUISA AGROPECUÁRIA BRASILEIRA - EMBRAPA. Manual e métodos de análise de solo. 2. ed. Rio de Janeiro: Centro Nacional de Pesquisa de Solos, 1997. $212 \mathrm{p}$.

FAGERIA, N. K.; BALIGAR, V. C. Enchancing nitrogen use efficiency in crop plants. Advances in Agronomy, New York, v. 88, n. 1, p. 97-185, 2006.

FERREIRA, D. F. SISVAR 4.6 - Sistema de análises estatísticas. Lavras: UFLA, 2003. 32 p.

FLORES, P.; CARVAJAL, M.; CERDA, A.; MARTINEZ, V. Salinity and ammonium/nitrate interactions on tomato plant development, nutrition, and metabolites. Journal of Plant Nutrition, Philadelphia, v. 24, n. 10, p. 1561-1573, 2001.

FLOWERS, T. J. Improving crop salt tolerance. Journal of Experimental Botany, Oxford, v. 55, n. 396, p. 307319, 2004.

FREIRE, E. de A.; LIMA, V. L. de; SANTOS JUNIOR, J. A.; NASCIMENTO, N. V. do; BELTRÃO, N. E. de M. Crescimento inicial do pinhão manso irrigado com água residuária sob doses crescentes de composto orgânico. Revista Educação Agrícola Superior, Brasília, v. 24, n. 2, p. 102-106, 2010.

KAFKAFI, U. Plant nutrition under saline conditions. In: SHAINBERG, I.; SHALHEVET, J. (Ed.). Soil salinity under irrigation: processes and management. Berlin: Springer-Verlag, 1984. p. 319-338.

LACERDA, C. F.; CAMBRAIA, J.; OLIVA, M. A.; RUIZ, H. A.; PRISCO, J. T. Solute accumulation and distribution shoot and leaf development in two sorghum genotypes under salt stress. Environmental and Experimental Botany, Amsterdam, v. 49, n. 2, p. 107120, 2003.

LAVRES JÚNIOR, J.; BOARETTO, R. M.; SILVA, M. L. S.; CORREIA, D.; CABRAL, C. P.; MALAVOLTA, E. Deficiência de macronutrientes no estado nutricional da mamoneira cultivar Íris. Pesquisa Agropecuária Brasileira, Brasília, v. 40, n. 2, p. 145-151, 2005.

LEONARDO, M.; BROETTO, F.; BÔAS, R. L. V.; ALMEIDA, R. S.; MARHCESE, J. A. Produção de frutos de pimentão em diferentes condições salinas. Revista Irriga, Botucatu, v. 12, n. 1, p. 73-82, 2007.

MEDEIROS, J. F.; LISBOA, R. A.; OLIVEIRA, M.; SILVA JÚNIOR, M. J.; ALVES, L. P. Caracterização das águas subterrâneas usadas para irrigação na área produtora de melão da Chapada do Apodi. Revista Brasileira de Engenharia Agrícola e Ambiental, Campina Grande, v. 7, n. 3, p. 469-472, 2003. 
MENEZES, R. P. B.; ANTUNES, A. M. S. Geração do conhecimento através da especificação de produtos químicos. Química Nova, v. 28, p. 100-103, 2005. Suplemento.

MILANI, M. BRS energia. 3. ed. Campina Grande, PB: Embrapa Algodão, 2010. (Folder).

MOSHKIN, V. A. Growth and development of the plant. In: p. $36-42$. . (Ed.). Castor. New Delhi: Amerind, 1986.

NERY, A. R.; RODRIGUES, L. N.; SILVA, M. B. R.; FERNANDES, P. D.; CHAVES, L. H. G.; DANTAS NETO, J.; GHEYI, H. R. Crescimento do pinhão-manso irrigado com águas salinas em ambiente protegido. Revista Brasileira de Engenharia Agrícola e Ambiental, Campina Grande, v. 13, n. 5, p. 551-558, 2009.

NOVAIS, R. F.; NEVES J. C. L.; BARROS, N. F. Ensaio em ambiente controlado. In: OLIVEIRA, A. J. Métodos de pesquisa em fertilidade do solo. Brasília: EmbrapaSEA, 1991. p. 189-253.

OLIVEIRA FILHO, A. F. de; OLIVEIRA, F. de A. de; MEDEIROS, J. F. de; MESQUITA, T. de O.; ZONTA, E. Crescimento de cultivares de mamoneira sob doses de torta de mamona. Revista Verde de Agroecologia e Agricultura Sustentável, Mossoró, v. 5, n. 5, p. 18-24, 2010.

OLIVEIRA, F. A. de; OLIVEIRA FILHO, A. F. de; MEDEIROS, J. F. de; ALMEIDA JUNIOR, A. B.; LINHARES, P. C. F. Desenvolvimento inicial da mamoneira sob diferentes fontes e doses de matéria orgânica. Revista Caatinga, Mossoró, v. 22, n. 1, p. 206211, 2009.

OLIVEIRA, F. A. de; OLIVEIRA, F. R. A. de; CAMPOS, M. S.; OLIVEIRA, M. K. T. de; MEDEIROS, J. F. de; SILVA, O. M. P. da. Interação entre salinidade e fontes de nitrogênio no desenvolvimento inicial da cultura do girassol. Revista Brasileira de Ciências Agrárias, Recife, v. 5, n. 4, p. 479-484, 2010.

OLIVEIRA, M. K. T.; OLIVEIRA, F. A.; MEDEIROS, J. F.; LIMA, C. J. G. S.; GUIMARÃES, I. P. Efeito de diferentes teores de esterco bovino e níveis de salinidade no crescimento inicial da mamoneira (Ricinus communis L.). Revista Verde de Agroecologia e Agricultura Sustentável, Mossoró, v. 1, n. 1, p. 68-74, 2006.

RHOADES, J. D.; KANDIAH, A.; MASHALI, A. M. Uso de águas salinas para produção agrícola. Campina Grande: UFPB, 2000. 117 p. (Estudos da FAO, Irrigação e Drenagem, 48, revisado).

RICHARDS, L. A. Diagnosis and improvement of saline and alkali soils. Washington: U.S. Department of Agriculture, 1954.

RODRIGUES, H. C. A.; CARVALHO, S. P.; SOUZA, H. A.; CARVAlHO, A. A. Cultivares de mamoneira e adubação nitrogenada na formação de mudas. Acta Scientiarum. Agronomy, Maringá, v. 32, n. 3, p. 471-476, 2010.

SEVERINO, L. S.; VALE, L. S.; BELTRÃO, N. E. de M. Método para medição da área foliar do pinhão manso. In: CONGRESSO DA REDE BRASILEIRA DE TECNOLOGIA DO BIODIESEL, 1., 2006, Brasília. Anais... Brasília: IBPS, 2006. p. 73-77.

SILVA, S. M. S.; ALVES, A. N.; GHEYI, H. R.; BELTRÃO, N. E. de M.; SEVERINO, L. S.; SOARES, F. A. L. Desenvolvimento e produção de duas cultivares de mamoneira sob estresse salino. Revista Brasileira de Engenharia Agrícola e Ambiental, Campina Grande, v. 12, n. 4, p. 335-342, 2008.

SOUZA JUNIOR, S. P.; SOARES, F. A. L.; SIQUEIRA, E. C. S.; GHEYI, H. R.; FERNANDES, P. D.; BELTRÃO, N. E. de M. Germinação, crescimento e produção do algodoeiro colorido BRS verde sob estresse salino. Revista Brasileira de Engenharia Agrícola e Ambiental, Campina Grande, v. 9, p. 236-241, 2005. Suplemento.

TESTER, M.; DAVENPORT, R. $\mathrm{Na}^{+}$tolerance and $\mathrm{Na}^{+}$ transport in higher plants. Annals of Botany, London, v. 91, n. 3, p. 503-527, 2003.

YAHYA, A. Salinity effects on growth and on uptake and distribution of sodium and some essential mineral nutrients in sesame. Journal of Plant Nutrition, Philadelphia, v. 21, n. 7, p. 1439-1451, 1998. 